\title{
DESIGN OF GOVERNMENT CLOUD NETWORK FOR A DEVELOPING ECONOMY: A CASE STUDY ONDO STATE
}

\author{
M. T. Owoseni ${ }^{1,{ }^{*}}$ and F. M. Dahunsi ${ }^{2}$

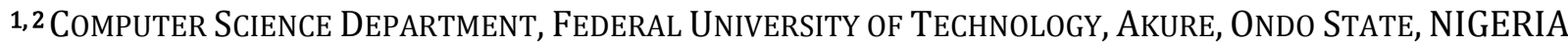 \\ E-mail addresses:1 mtowoseni@futa.edu.ng,2fmdahunsi@futa.edu.ng
}

\begin{abstract}
In Ondo State, some businesses, telecommunication agencies and government agencies are not utilizing Information Technology (IT) services to its maximum due to challenges faced by IT penetration in the state. This paper presents the design of a Government Cloud (G-Cloud) network for Ondo State Government which will provide Infrastructure as a Service (IaaS) and Software as Service (SaaS) to major government establishments and citizens within Ondo State. In designing the G-Cloud a mathematical model of cloud computing data center was adapted to design the network; and specifications from cloud management software were used to deploy the (AMD)-Virtualized server. The simulation results from CloudAnalyst and Cloudsim show that utilizing one data center with 50Vitual Machines (VMs) the response time is $201.10 \mathrm{~ms}$ and on increasing the number of data center to five with 50VMs per data center, the response time reduced to 56.10ms. The paper proposes a G-Cloud with five data centers that can be adopted by the state government to close the digital divide gap, or a start-up G-Cloud with one data center at a lower cost.
\end{abstract}

Keywords - Cloud Computing, Government Cloud Network, Datacenter and Ondo State.

\section{INTRODUCTION}

Cloud computing is becoming a buzz word in Information Technology (IT) world as a result of the advantages attached to it. It limits the cost incurred in acquiring computing infrastructure, high availability and scalability of services on a pay-as-you-use basis thereby making computing more easier and convenient for business and government organizations.

Cloud computing is a computing model which enables convenient, on-demand network access, to a shared pool of configurable computing resources such as networks, servers, storage, applications, and services that can be rapidly provisioned and released with minimal management effort or service provider interaction [1]. Part of the objectives of cloud computing are pay-as-you-go, elasticity and multitenancy [2]. Cloud services accessed can be Infrastructure as a Service (IaaS), Platform as a Service (PaaS) and Software as a Service (SaaS). Deployment models identified for cloud architectural solutions are four; public cloud, private cloud, community cloud and hybrid cloud [3].
A Government cloud refers to a cloud computing network that is owned and operated by government which renders all cloud services (Infrastructure as a Service, Platform as a Service and Software as a Service) to citizens for free. Government documents, applications and files are deployed on G-cloud for access to users from various localities. Government cloud reduces processing time, improves interaction with citizens through efficient and effective services, influence service provision to citizens and provides access to adequate information [4].

Different Government clouds have been adopted in some countries like Australia, South Africa, Greece, Taiwan and Ireland to reduce the cost incurred in Information Technology (IT) infrastructures and maximize cloud storage capacity usage. The system architecture of the software systems used in the delivery of cloud computing, involves multiple cloud components that communicates with each other over application programming interfaces (APIs), usually web services [5]. Cloud architectures are designs of software applications that use internet-accessible ondemand services [6]. The major components of 
Government cloud architecture are front end and back end. The front end is the application through which the user accesses the cloud via a user interface like web browser while the back end is the 'cloud' itself, that consist of various computers, servers and data storage devices [5].

In Ondo State, some businesses, telecommunication agencies and government agencies are not utilizing IT services to its maximum due to IT penetration challenges in the State. These include irregular power supply, limited network coverage, cost of IT infrastructures, cost and expertise of IT personnel. Hence the need for Government cloud that provides solution such as reduction in the cost of IT infrastructures, high efficiency and availability of services such as infrastructure as a service and software as a service in Ondo State as well as unlimited storage capacity with fast processing power. This paper presents the design of Government cloud network for a developing economy; a case study of Ondo State and analyzes bench mark for the designed G-Cloud. The proposed G-cloud will serve as a platform for hosting educational applications and documents for schools and institutions, healthcare applications for patients, financial applications for collaborative work, agricultural applications for weather forecast, and as back-up for government documents and records.

\section{RELATED WORKS}

Research on design of Government Cloud is still in its early stage; therefore, related works are mainly describing the adoption level of cloud computing in government services in Europe countries like Austria, Denmark, Finland, Germany, Ireland, Spain and United Kingdom. France is one of those countries that favour the development and installation of a nation-wide cloud for government called "Andromeda" in 2011 [1]. Meanwhile the objectives of the G-cloud implemented and installed are to reduce IT (Information Technology) costs for governments, optimizing data center infrastructure usage, and increasing public sector agility [1].

The main infrastructure in cloud computing is the data center. Three-tier data center architectures are the most common nowadays which include access, aggregation, and core layers. This aggregation layer allows the increase in the number of server nodes (to over 10,000 servers) and keeps inexpensive Layer 2 (L2) switches in the access network, which provides a loop free topology [7]. A larger percentage of the energy consumed by the data center is utilized to maintain interconnection links and network equipment operations. The rest of the electricity is wasted in the power distribution system, dissipated as heat energy, and used up by air-conditioning systems [7].

To allow control and repeatability of experiments in cloud computing environment, simulators such as CloudSim and CloudAnalyst are used. Simulation experiments apply models of both applications and infrastructures [8]. [8] modeled the behavior of social networking applications (such as Facebook) with CloudSim and evaluated the costs and performance implications. The performance analysis showed that One (1) datacenter with 50VM (Virtual Machines), two (2) datacenter with 50VM and three (3) with $50 \mathrm{VM}$, gave $1057.75 \mathrm{~ms}, 943.40 \mathrm{~ms}$ and $901.38 \mathrm{~ms}$ response time respectively when simulated with CloudAnalyst. This implies that bringing the service closer to the users improves the quality of service. Service quality was further improved by applying throttled load balancing algorithm at the application level across data centers and also at virtual machine levels within datacenters. Hence the response time became faster.

It has also been proved that service quality can be further improved with the application of load balancing algorithm in the data centers, which is managed by service brokerage policies. [9][10] demonstrated how CloudAnalyst is used to model and evaluate a real world problem; of social networking application deployed on the cloud. The experiment presented new features, issues on modeling and evaluating new mechanisms and algorithms for resource management.

CloudAnalyst was proposed in [9] to model the behavior of social network application (Facebook) and to simulate this application deployed on Cloud Infrastructures. The first model consists of a single datacenter with 50VM used to host the social network application. The second model consists of the use of two datacenters, each one with 25VM dedicated to the application. The third model consists of two datacenters, each one with 50VM without load sharing between them. In the fourth model, two datacenters each with 50VM share the load during peak time; by applying peak load sharing and queuing algorithm. Their average response time are $284.98 \mathrm{~ms}$ (milliseconds), $249.20 \mathrm{~ms}, \quad 183.85 \mathrm{~ms} \quad 184.92 \mathrm{~ms}$ respectively. Simulation results shows that bringing the service closer to users improves the quality of 
service (response time) which is an expected effect, because users experience less effect from internet issues when they are geographically close to the application server. Also, load sharing during peak time contributed to reduction in response time which improves the performance of the designed cloud network.

In [10] Service quality was further improved by the application of load balancing at the application level across data centers (by different service brokerage policies). The sufficient capacity of the datacenter enabled it to meet peak demand, but when the capacity is not fully utilized, the resources are being wasted. Hence a dynamic service broker was adapted which optimize the performance while keeping the cost down. The first model consists of one datacenter with 50VM used to host a social network application. The second model consists of two datacenters, each one with 50VM peak load sharing. The third model consists of two datacenters, each one with 50VM peak load sharing and throttling. The fourth model consists of three datacenters each one with 50VM peak load sharing and throttling. The fifth model consists of three datacenters each one with 75, 50, 25 VMs, peak load sharing and throttling. The average response time was $7965.50 \mathrm{~ms}, 6716.65 \mathrm{~ms}, 3497.44 \mathrm{~ms}$, $3184.58 \mathrm{~ms}$ and $2698.13 \mathrm{~ms}$ respectively. The performance changes as the number of datacenters increases, and the introduction of peak load sharing and throttling made the response time faster and better.

[11] presents the design of the network infrastructure of a Data Center that meets the requirements arising from Cloud Computing used in the Health Sector of Arequipa city. Focus was on network layer 2 and its dimensionality to meet the requirements of several health service applications. The network infrastructure dimensionality calculation is a complex challenge for the ground project. Therefore a novel approach to solve this challenge was presented. Criticality, capacity and growth were identified as the technical mechanisms required for the design of network infrastructure Cloud Data Center. Criticality; through which we can choose according to the characteristics of applications available network; Capacity and Growth, these design factors set out to find the maximum and minimum network load and an expansion margin considering it should be a short time, because it is active equipment and technology in general.
In [12] the design of Cloud Computing structures on computer systems which include new designs in global economic development was considered. It examines the technical cloud computing structures (which include physical infrastructure, virtual structure and application/users), consider the technical (cyber security and infrastructure management) and ethical issues in designing effective sites, and consider the impact of cloud computing on reshaping computer education programs to include enterprise systems. It was revealed that cloud computing can be used to deploy software, textbooks and journals for people to learn computing.

Existing literatures do not give detailed design and performance analysis of a G-Cloud network with different users and uses. This research work was able to design a G-Cloud network and show performance evaluation of the proposed network.

\section{DESIGN OF PROPOSED GOVERNMENT CLOUD}

Cloud users in Ondo State can be broadly divided into two classes; major users (government workers) and casual users (citizens). There are 79 different towns/villages in the local government areas of major cities chosen as coverage area in Ondo State. Based on statistics $60 \%$ of the citizens are literates and out of which $40 \%$ are IT literates [13]. According to commissioner for information when interviewed, about 1000 people are government IT personnel in the state. The proposed Government-cloud is a hybrid cloud which comprises of Community Cloud and Private Cloud. One-third of the servers in each data center is designed as a Community Cloud meant for the citizen while the remaining two-third of the servers are designed for the Private Cloud meant solely for the State government administration. Two types of service models are also proposed; Infrastructure as a Service (IaaS) and Software as a Service (SaaS). These services are rendered to citizens and government establishments as Government to Business (G2B), Government to Citizen (G2C), Government to Agency (G2A) and Government to Employee (G2E) services.

\subsection{Data Center}

A data center is the major infrastructure in cloud computing which houses several servers and switches that are logically connected via cables and on which the various applications that drive the cloud are installed as well as the user's applications. For the purpose of this design work, three-tier data center 
architecture is proposed because it implements an 8way ECMP(The Equal Cost Multi-Path routing) that includes 10 GE Line Aggregation Groups (LAGs), which allows a network client to address several links and network ports with one MAC address [7]. To design a Government Cloud for a minimum of 1000 users based on number of government IT personnel [11], it is assumed that each user will have a minimum of $1 \mathrm{~TB}$ storage and $20 \%$ of total storage in data center as redundant storage in a G-cloud of 5 data centers.

Where

$$
\text { Total internal storage }=1000 T B
$$

Therefore:

Active servers/data center

$$
\begin{aligned}
& =200 \text { servers }(\times 5 \text { data centers }) \\
& =1000 \text { servers }
\end{aligned}
$$

Redundant servers/data center

$$
\begin{aligned}
& =40 \text { servers }(\times 5 \text { data center } \\
& =200 \text { servers }
\end{aligned}
$$

No of servers per data centre $=240$ servers

$$
\text { External storage/data center }=100 P B
$$

The data center is designed to have 240 servers (200 active and 40 redundant servers) with $100 \mathrm{~PB}$ of external storage.

\subsection{Mathematical Model of Data Center Design}

Some of the equations used were adapted from [12], the cloud devices include nodes, switches, storages and the control device in the data center that are connected together via links with node, switch, storage and link functions. The Cloud data center can be defined as a weighted undirected graph of the form:

$$
\text { Cloud }=\left(\text { Devices, } \operatorname{Links,} \text { Type }\left(w_{n}, w_{s w}, w_{s t}, w_{l}\right)\right)
$$

where the set of vertices denotes network devices and $w_{n}, w_{s w}, w_{s t}, w_{l}$ are function for node, switch, storage and link respectively;

Devices $=$ Nodes $\cup$ Switches $\cup$ Storages

$$
\cup \text { Contro }
$$

\subsubsection{Design of Computing Nodes}

Computing Nodes: Nodes $=\left\{N_{1}, N_{2}, \ldots N_{n}\right\}$

number of nodes is given as 240 from equation 3

\subsubsection{Design of Switches}

Switches: Switches $=\left\{S_{1}, S_{2}, \ldots S_{m}\right\}$

\subsubsection{Design of the Network Storage}

Network storages: Storages $=\left\{F_{1}, F_{2}, \ldots, F_{r}\right\}$

number of storages $=5$ storages

because $100 P B$ of storage is to each data center and

\subsubsection{Design of the Control:}

Control: special computing node executing the network operating system. It controls access between community cloud and the private cloud meant for government officials from being tampered with by the citizens

\subsubsection{Design of Edges and Communication media}

The communication link used for the design of the cloud network is fibre optic, which is judged as the best media for wired communication.

$$
\text { Edges: Links }=\left\{L_{i j}\right\}
$$

where

$[i j]=[i, \ldots, i ; j, \ldots, j]$ are bidirectional network links (edges) and number of links to devices

$$
\begin{gathered}
i=\text { OM4 multimode fiber cable for } \\
10 G \text { Ethernet (10GBase }-S R) \text { and } \\
j=\text { OM5 multimode fibre cable for } \\
\text { 40G Ethernet (40GBase }-S R 4)
\end{gathered}
$$

No of edges in the $G-$ Cloud network $=n(n-1) / 2$ where $n=$ no of nodes

$=240(240-1) / 2$

$=28680$ edges in each data center

the latency of each fiber cable can be gotten from

Latency $=$ lenght of fibr/Distance of specified wavelenght Distance $=$ speed of light $(299.792 \mathrm{~m}) /$ Refractive Index

e.g Distance $(G 652)=299.792 \mathrm{~m} /$ microsec $/ 1.4677$

$$
=204.260
$$

Latency of G652 single mode fibre $=100000 / 204.260$

$$
=489.5721 \text { microsec }
$$

Latency of multimode fibre $=125$ microsec $[13]$

\subsubsection{Design of Node Parameters}

Nodes Parameters: Function $w_{n}$ for each node $N_{i}$ is given as vector

$$
w_{n} \cdot\left(N_{i}\right)=\left(w_{n} \cdot \text { stat. }\left(N_{i}\right), w_{n} \cdot \text { dyn. }\left(N_{i},(t)\right)\right)
$$

where the static parameters are represented by a vector

$$
w_{n} \text {. stat. }\left(N_{i}\right)=\left(M_{i} D_{i} C_{i} P_{i}\right)
$$

Where RAM size, $M_{i}=512 G B$, local disk size, $D_{i}=1 T B$, computing cores count $C_{i}=16$, and their performance characteristics $P_{i}=\left\{P_{i 1}, P_{i 2}, \ldots, P_{i c i}\right\}$ = response time

the dynamic characteristics are represented by vector $w_{n} \cdot d y n .\left(N_{i}(t)\right)$

$$
=\left(m_{i}(t), d_{i}(t), u_{i k}(t), v m_{i}(t)\right)
$$

Where $m_{i}(t), d_{i}(t)$, respectively denote available RAM and disk size at the time $t \geq 0, u_{i k}(t),-$ utilization of node $N_{i}$ core $k$ at time $t$. $v_{i}(t)$ is a set of virtual machine instances running at the time $t$. 


\subsubsection{Design of Switch Parameters}

Switch Parameters: Function $w_{s w}$ for each switch $S_{j}$ is given as vector

$$
w_{s w}\left(S_{j}\right)=\left(w_{s w} \cdot \operatorname{stat}\left(S_{j}\right), w_{s w} \cdot \operatorname{dyn}\left(S_{j},(t)\right)\right)
$$

Static parameters of $S_{j}$ include the following values:

$$
w_{s w} \cdot \text { stat. }\left(S_{j}\right)=\left(T_{j}, P_{j}\right)
$$

where $T_{j}$

$\in\{" 10 G$ Ethernet" $\}$ which denotes supported version of Ethernet protocol and

$$
P_{j} \text { is a number of switch ports }=40 \text { ports }
$$

The Ethernet protocol for this cloud network is $10 G$ Ethernet with

\subsubsection{Design of Storage Parameters:}

Any storage $F_{k}$ has vector of characteristics

$$
w_{s t}\left(F_{k}\right)=\left(v_{k}, v k(t)\right)
$$

where $v_{k}-$ maximum size of storage $=100 P B$, $v_{k}(t)$-its current size at the time $t$

\subsubsection{Design of Link Parameters:}

For each network link $l_{i j} \in L$

$w_{l} .\left(l_{i j}\right)=\left(B_{i j}\right.$, Lat $_{i j}, b_{i j}$, lat $\left._{i j}(t)\right)$

Where $B_{i j}$ is a maximum bandwidth of network link,

$$
\begin{gathered}
\text { Lat }_{i j} \text { is maximum latency, } \\
b_{i j}(t)-\text { current bandwidth at the time } t,^{\text {lat }_{i j}(t)-\text { current latency. }}
\end{gathered}
$$

The last two characteristics consider network contention. Figure 1 shows the connectivity of the designed vertices in the proposed three-tier data center

Each data center has six (6) E7Y64A switches; with forty (40) ports of sixteen (16) $\mathrm{Gb} / \mathrm{s}$ bandwidth are used to connect two-hundred and forty (240) Dell Power Edge M905 servers in Layer 1. This makes forty (40) servers per rack which are connected to a switch via OM4 multimode fiber for 10G Ethernet. Three (3) pairs of QK710C switches are used in Layer 2 to mesh the six (6) switches in Layer 1 together through OM4 multimode fiber for 40G Ethernet (40GBase-SR4). And in Layer 3, three (3) QK710C switches are used to mesh Layer 2 switches into a cluster of servers through OM4 multimode fiber for 40G Ethernet. And this Layer 3 switches serves user's request.

A summary of the hardware components of the designed cloud include server, switches and cables. Hardware deployed are: server - M905 server, Layer 1 switch - E7Y64A, Layer 2 switch - QK710C, Layer 3 switch - QK710C. For cables - OM4 multimode fibre cables of 10GE for Layer 1and Layer 2, OM4 multimode fibre cables of 40GE for Layer 3 and G652 single mode fiber as the back bone. For storage - Dell Equallogic series was deployed and for WiMAX - IEEE 802.16e-compliant WiMAX was deployed. For Radio Cisco Radio - 802.11g Aironet 1400 series was deployed and for Data center cooling machine Liebert HPC - S Free cooling Chiller was deployed.

\subsection{Other Design Parameters}

Other design parameters considered includes server architecture, cloud management software, medium of connectivity, and electricity supply to data centers.

Multi-mode fibers (MMF) are designed to be deployed within data center networks while single-mode fibers are deployed for connecting the data centers in a fibre ring because they permit transmission over long distances with higher bandwidth (data rates) than wire cables and with less loss.

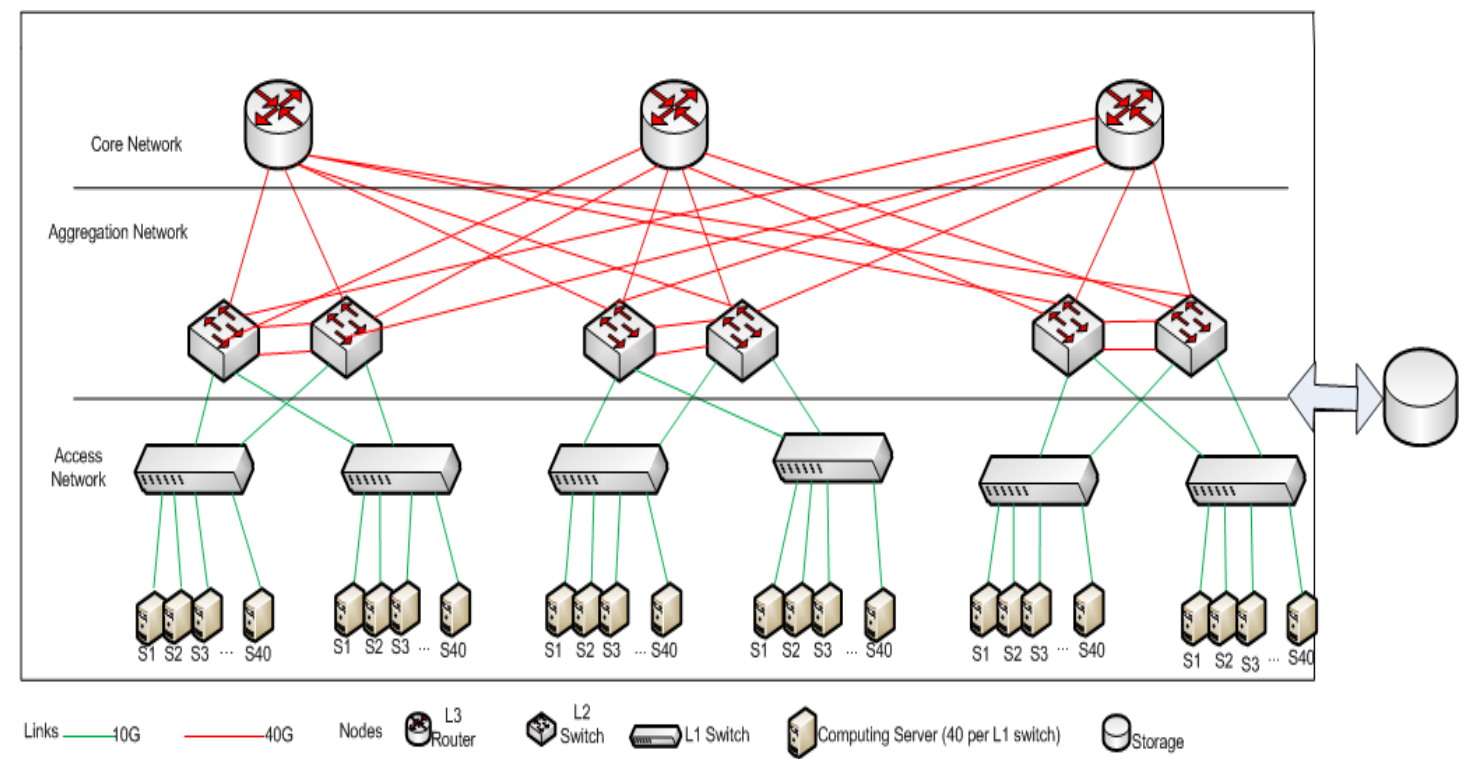

Figure 1 Connection of vertices in the designed data center 
The optic fibre cable is deployed to connect data centers internally and externally while a WiMAX (Worldwide Interoperability for Microwave Access) is used to transmit signals to various radios in designated clients' environment since it will be too expensive to run the whole State with fibre cables. And these radios will transmit to various client channels. Cisco IEEE 802.16e-compliant WiMAX is proposed to deliver last mile wireless broadband access as an alternative to cable by each datacenter to users via Cisco Radio - 802.11g. This is because the cost of running fibre optic cable all through the State will be too enormous.

In order to improve the quality of service (response time), the G-cloud is designed with five (5) data centers connected in fibre ring after different simulation scenarios were considered. The proposed data centers are situated in Akoko, Owo, Akure, Ondo and Okitipupa so that users can be closer to application servers to ensure download and upload speed.

The software requirement of Government cloud includes Virtual Machine, Hypervisor, Deployment software, Management software. The virtual infrastructure manager deployed is Open Nebula release 4.4 which manages heterogeneous distributed data center infrastructures with AMD -V Opteron processor and it is open-source software [16]. Furthermore, a logical server architect is proposed. They are delivered through server virtualization which is the specification of cloud management software deployed (i.e. Open Nebula) that requires virtualization based servers.

To ensure security of proposed infrastructure, a right of way and marking are used to safeguard the network or information deployed over it from any form of interruption and for save delivery of packets. For network security, symmetric encryption is recommended to protect messages from unauthorized access. According to [17] in symmetric encryption, a single key is used both to encrypt and decrypt traffic. Firewall and Honey pot are also recommended to safe guard servers (data centers) from hackers, viruses and worms over the internet. Electric power from the Electricity billing company is proposed and in case of power outage a stand-by generating plant will substitutes the power source thereby ensuring that the cloud network is up at all time.

\section{SIMULATION OF DESIGNED G-CLOUD}

CloudSim and CloudAnalyst are cloud simulators [10] [8], and they are the simulators used to simulate the designed G-Cloud network. A CloudSim is a framework for modeling and simulation of cloud computing infrastructures and applications. CloudSim framework is built on top of GridSim toolkit. CloudAnalyst is a cloudsim-based visual modeller for analyzing cloud computing environments and applications. The CloudAnalyst also enables a modeler to repeatedly execute simulations and to conduct a series of simulation experiments with slight parameters variations in a quick and easy manner.

In designing the CloudAnalyst five (5) user bases model a group of users in five (5) different geographical regions. Where region $0=$ Akure, $1=$ Ondo, 2 = Okiti-pupa, $3=$ Akoko, $4=$ Owo. For simplicity each user is contained within a time zone and assumed that most users use the application during working hours for about 2 hours within 8GMT to 6GMT. It was assumed that one tenth of simultaneous online users during peak hours were online during off peak hours and that each user makes a new request every 5 minutes when online; which implies that a total of 24 request/ $2 \mathrm{hr}$ is made and the data size of each request is 100 byte/request. The hardware components of G-cloud are modeled into 'main configuration', 'data center configuration' and 'advanced'. The value for each component according to the configuration presented in Table 1 is inputted and simulated to generate the processing time and response time after each simulation.

\subsection{Determining the Choice of Load Balancer}

Comparative analysis was carried out on the Throttled Load Balancer (TLB) and Active Monitoring Load Balancer (AMLB), and on changes in number of data centers and virtual machines.

Table 1: Hardware Specification for proposed Government Cloud

\begin{tabular}{ll}
\hline Parameter & Value \\
\hline VM Image Size & 10000 \\
VM Memory & 10240 \\
VM Bandwidth & 10000 \\
Data Center - Architecture & X86 \\
Data Center - OS & Linux \\
Data Center - VMM & Xen \\
Data Center - Number of Machines & 240 \\
Data Center - Memory per Machine & $512 \mathrm{~GB}$ \\
Data Center - Storage per Machine & $1 \mathrm{~TB}$ \\
\hline
\end{tabular}




\begin{tabular}{ll}
\hline Parameter & Value \\
\hline $\begin{array}{l}\text { Data Center - Available Bandwidth per } \\
\text { machine }\end{array}$ & 10000 \\
$\begin{array}{l}\text { Data Center - Number of Processors } \\
\text { per Machine }\end{array}$ & 4 \\
Data Center - Processor Speed & 10000 \\
Data Center - VM Policy & Time Shared \\
User Grouping Factor & 1000 \\
Request Grouping Factor & 100 \\
Executable Instruction Length & 250 \\
\hline
\end{tabular}

Table 2 Simulation Result for Throttled Load Balancer (TLB) and Active Monitoring Load Balancer (AMLB) (5 data centers and 50VM)

\begin{tabular}{llllll}
\hline \multirow{2}{*}{ Scenario } & $\begin{array}{l}\text { Number of } \\
\text { Users }\end{array}$ & \multicolumn{2}{l}{$\begin{array}{l}\text { Response Time } \\
\text { (milliseconds) }\end{array}$} & \multicolumn{2}{l}{$\begin{array}{l}\text { Processing time } \\
\text { (milliseconds) }\end{array}$} \\
\cline { 3 - 6 } & TLB & AMLB & TLB & AMLB \\
\hline 1 & 1000 users & 51.94 & 52.10 & 2.09 & 2.18 \\
2 & 2000 users & 52.10 & 52.74 & 2.18 & 2.58 \\
3 & 3000 users & 52.74 & 53.36 & 2.58 & 3.08 \\
4 & 4000 users & 53.41 & 53.84 & 3.03 & 3.31 \\
5 & 5000 users & 53.84 & 53.58 & 3.31 & 3.79 \\
6 & 6000 users & 54.53 & 54.90 & 3.71 & 4.03 \\
7 & 7000 users & 54.90 & 55.03 & 4.03 & 4.10 \\
8 & 8000 users & 55.03 & 55.40 & 4.10 & 4.43 \\
9 & 9000 users & 55.19 & 55.69 & 4.43 & 5.19 \\
10 & 10000 & 56.10 & 56.81 & 4.84 & 5.21 \\
& users & & & & \\
\hline
\end{tabular}

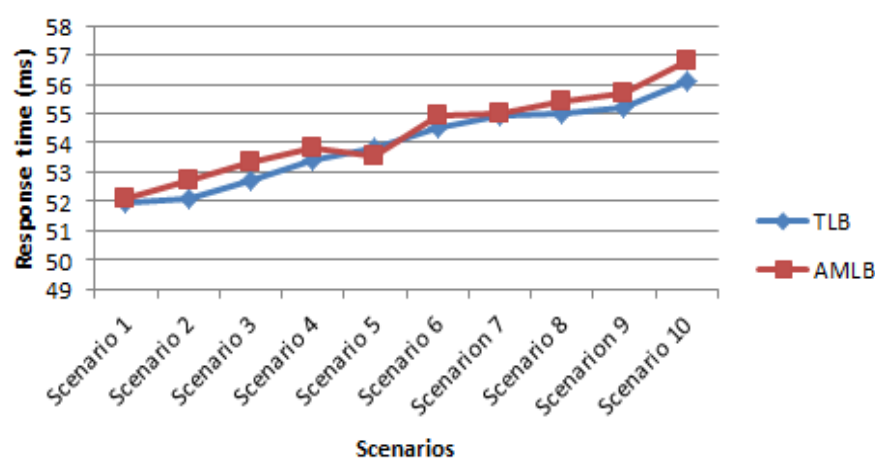

Figure 2 Response time for Throttled Load Balancer(TLB) and Active Monitoring Load Balancer (AMLB)

Scenario one: Simulation Result for Throttled Load Balancer (TLB) and Active Monitoring Load Balancer (AMLB) (5 data centers and 50VM)

In the proposed cloud, two different Virtual Machine Load Balancer techniques were simulated to see which technique has a better response time with varied number of users ranging from one thousand to ten thousand users $(1,000 \ldots 10,000)$ over five (5) data centers with 50VMs deployed on each data center. The simulation result revealed that with 1,000 users, the response time on throttled load balancer is $51.94 \mathrm{~ms}$ which is lesser to the response time of active monitoring load balancer which was $52.10 \mathrm{~ms}$. And at 10,000 users the response time $56.10 \mathrm{~ms}$ of throttled load balancer was smaller compared to $56.81 \mathrm{~ms}$ response time of active load balancer. With these differences in response time, it is confirmed that throttled load balancer has better performance compared to active load balancer as shown in Table 2 and Figure 2; where TLB deflects from AMLB curve downwardly to show that TLB has lesser response time at points of deflection

Scenario two: Comparative analysis was carried out on changes in number of data centers and virtual machines

Results presented in Table 3 and Figure 3 show that one data center with 50VMs has a response time of $201.10 \mathrm{~ms}$. When the number of data center got increased to 5 with $50 \mathrm{VMs}$ per data center, the response time of designed G-cloud reduced to $56.10 \mathrm{~ms}$. Hence 5 data centers with 50 virtual machines and throttled VM load balancer with service proximity based routing for the proposed Government cloud is established.

This shows that the higher the number of data centers the faster the response time. Also the adoption of peak load sharing and throttling with increase in the number of datacenter with higher resource configuration made the designed network to have better network performance than the existing one.

This research work adapted different models such as mathematical model, existing simulator and server specification from cloud management software to ensure optimal utilization of information technology platforms and services in Ondo State, Nigeria.

This research work adapted existing models to a large number of people and caters for different requirements of different users compared to existing work.

Table 3 Comparative Analysis based on changes in number of data centers and virtual machines

\begin{tabular}{llcc}
\hline S/N & Scenario & response time $(\mathrm{ms})$ & processing time $(\mathrm{ms})$ \\
\hline 1 & 1 data center with 50VMs & 201.10 & 6.85 \\
2.1 & 2 data center with 25VMs each & 170.25 & 20.41 \\
2.2 & 2 data centers with 50VMs each & 112.40 & 9.30 \\
\hline
\end{tabular}




\begin{tabular}{|c|c|c|c|}
\hline $\mathrm{S} / \mathrm{N}$ & Scenario & response time $(\mathrm{ms})$ & processing time $(\mathrm{ms})$ \\
\hline 2.3 & 2 data center with $50 \mathrm{VM}$ s each with peak load sharing & 113.65 & 8.25 \\
\hline 2.4 & $\begin{array}{l}2 \text { data center with } 50 \mathrm{VMs} \text { each with peak load sharing } \\
\text { and throttling }\end{array}$ & 101.35 & 4.42 \\
\hline 2.5 & $\begin{array}{l}3 \text { data centers with } 50 \mathrm{VMs} \text { each with peak load sharing } \\
\text { and throttling }\end{array}$ & 85.20 & 4.57 \\
\hline 2.6 & $\begin{array}{l}4 \text { data centers with } 50 \mathrm{VMs} \text { each with peak load sharing } \\
\text { and throttling }\end{array}$ & 70.42 & 4.71 \\
\hline 2.7 & $\begin{array}{l}5 \text { data centers with } 50 \mathrm{VMs} \text { each with peak load sharing } \\
\text { and throttling }\end{array}$ & 56.10 & 4.84 \\
\hline 2.8 & $\begin{array}{l}5 \text { data centers with } 75,65,50,45,15 \mathrm{VMs} \text { with peak load } \\
\text { sharing and throttling }\end{array}$ & 56.19 & 4.86 \\
\hline
\end{tabular}

Table 4 Cost Analysis of Designed Government Cloud

\begin{tabular}{llll}
\hline Requirement & Specification & Cost/item ( $)$ & Total Cost (\#) \\
\hline Server & M905 servers & & \\
Layer 1 & 240 pieces & $2,075,223.15$ & $498,053,556$ \\
Cable & Fibre cable & $2,318,798.09$ & $2,318,798.09$ \\
Layer 1 & Multi-mode cable (10GE) & $2,522,978.84$ & $2,522,978.84$ \\
Layer 2 & Multi-mode cable (40GE) & $2,522,978.84$ & $2,522,978.84$ \\
Layer 3 & Multi-mode cable (40GE) & $2,662,096.82$ & $2,662,096.82$ \\
Back bone & Single-mode cable (40GE) & & \\
Switches & & $12,062,019.216$ & $72,372,115.296$ \\
L1 switches & 6 pieces of E7Y64A & $20,445,193.2425$ & $122,671,159.455$ \\
L2 switches & 6 pieces of QK710C & $9,231,667.4385$ & $27,695,002.3155$ \\
L3 switches & 3 pieces of MDS 9700 & $1,646,500$ & $1,646,500$ \\
Storage & 1 piece of Dell Equal Logic & & $6,400,000$ \\
Cooling machine & 4 pieces of Liebert HPC-S Free cooling Chiller & $1,600,000$ & $738,865,185.6565$ \\
Total & & & $738865185.6565 \times 5$ \\
Total for 5 data centers & & & $3,694,325,928.2825$ \\
\hline
\end{tabular}

\subsection{Cost Analysis of Designed Government Cloud}

According to [18], at the rate of $\$ 1$ to $\$ 176.15$, a total of seven hundred and thirty-eight million, eight hundred and sixty-five thousand, one hundred and eighty-five naira ( $\$ 738,865,185.6565$ ) is required per data center while three billion, six hundred and ninety-four million, three hundred and twenty-five thousand, nine hundred and twenty-eight ( $\mathrm{N} 3,694,325,928.2825)$ will be required to implement the proposed Government cloud of five data center. The detail analysis of this cost is shown in Table 4.

Table 5 Energy Implication of Designed Government

\begin{tabular}{lcc}
\multicolumn{3}{c}{ Cloud } \\
\hline \multicolumn{1}{c}{ Item } & $\begin{array}{c}\text { Energy requirement/ } \\
\text { item }(\mathrm{kw} / \mathrm{hr})\end{array}$ & $\begin{array}{c}\text { Total } \\
(\mathrm{kw} / \mathrm{hr})\end{array}$ \\
\hline Server M905 (1200) & 1.5 & 1800 \\
E7Y64A (30) & 0.5 & 15 \\
QK710C (30) & 0.5 & 15 \\
MDS 9700 (15) & 0.5 & 7.5 \\
Storage (E5400) & 0.75 & 3.75 \\
\hline Total & & 1841.25 \\
\hline
\end{tabular}

\subsection{Energy Implication of Designed Government Cloud}

According to [19], a total of $1,841.25 \mathrm{kw} / \mathrm{hr}$ of energy will be required in G-Cloud to power the resources. This is represented in Table 5.

\subsection{Comparative Analysis}

The performance of proposed cloud was compared with an existing work by[9]for request by a minimum of 10,000 users. The simulation result shows that the proposed G-Cloud has better performance than the existing work just as represented in Table 6. One data center with 50VMs on proposed G-Cloud has a response time of $201.10 \mathrm{~ms}$ while [9] has $284.98 \mathrm{~ms}$. And three data center with 50VMs on proposed GCloud has a response time of $85.20 \mathrm{~ms}$ while [9]was $124.12 \mathrm{~ms}$. Also with five data center and $50 \mathrm{Vms}$ the response time of proposed G-Cloud became $56.19 \mathrm{~ms}$ which is far better than [9] values. 


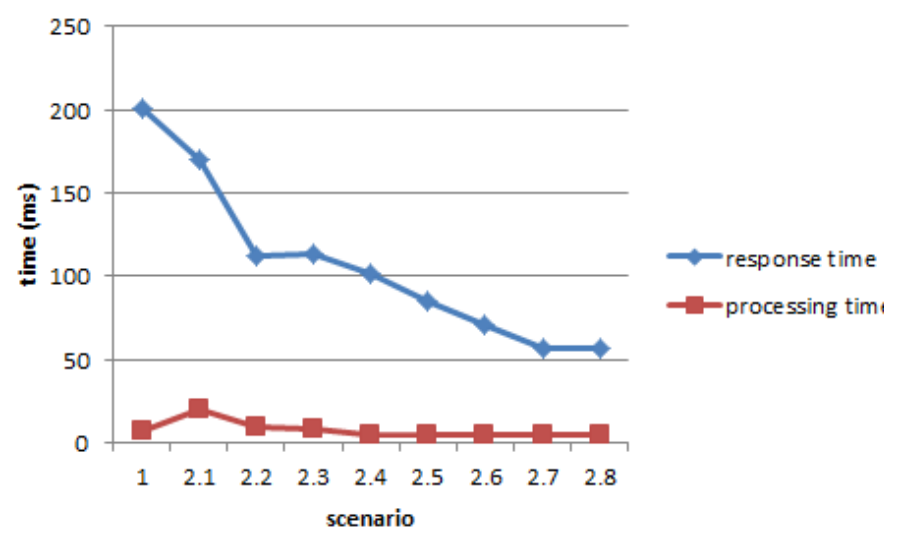

Figure 3 Comparative Analysis based on changes in number of data centers and virtual machines

Table 6: Wickremasinghe et al [10] simulation result in comparison with proposed G-Cloud

\begin{tabular}{|c|c|c|c|c|c|}
\hline \multicolumn{2}{|l|}{$\mathrm{S} / \mathrm{N}$} & \multicolumn{2}{|c|}{ Response time (millisecond) } & \multicolumn{2}{|c|}{ Processing time (milliseconds) } \\
\hline & Scenario & G-Cloud & $\begin{array}{l}\text { Wickremasinghe et } \\
\text { al (2010) }\end{array}$ & G-Cloud & $\begin{array}{l}\text { Wickremasinghe et al } \\
\text { (2010) }\end{array}$ \\
\hline 1 & 1 DC with 50VMs & 201.10 & 284.98 & 6.85 & 46.79 \\
\hline 2 & 2 DCs with 25VMs each & 170.25 & 249.20 & 20.41 & 119.97 \\
\hline 3 & 2 DCs with 50VMs each & 112.40 & 183.85 & 9.30 & 54.65 \\
\hline 4 & 2 DCs with 50VMs each with PLS & 113.65 & 184.92 & 8.25 & 54.60 \\
\hline 5 & $\begin{array}{l}2 \text { DCs with } 50 \text { VMs each with PLS } \\
\text { and queuing }\end{array}$ & 101.35 & 157.56 & 4.42 & 28.45 \\
\hline 6 & $\begin{array}{l}3 \text { DCs with 50VMs each with PLS } \\
\text { and throttling }\end{array}$ & 85.20 & 124.12 & 4.57 & 29.12 \\
\hline 7 & $\begin{array}{l}3 \text { DCs with } 75,50,15 \text { VMs with PLS } \\
\text { and throttling }\end{array}$ & & 121.07 & & 23.96 \\
\hline 8 & $\begin{array}{l}4 \text { DCs, } 50 \text { VMs each, PLS and } \\
\text { throttling }\end{array}$ & 70.42 & & 4.71 & \\
\hline 9 & 5 DCs, 50VMs, PLS and throttling & 56.10 & & 4.84 & \\
\hline 10 & $\begin{array}{l}5 \text { DCs. } 75,65,50,45,15 \mathrm{VMs}, \text { PLS } \\
\text { and throttling }\end{array}$ & 56.19 & & 4.86 & \\
\hline
\end{tabular}

Table 7 Model comparison of designed work and existing work based on metrics

\begin{tabular}{|c|c|c|c|}
\hline $\mathrm{S} / \mathrm{N}$ & Metrics & Proposed G-Cloud & Wickremasinghe et al [10] \\
\hline 1 & Size of VM & $10000 \mathrm{MB}$ & $100 \mathrm{MB}$ \\
\hline 2 & VM Memory & $10240 \mathrm{MB}$ & $1 \mathrm{~GB}$ \\
\hline 3 & Data center architecture & x86 & x86 \\
\hline 4 & VM monitor & Xen & Xen \\
\hline 5 & Machine operating system & Linux & Linux \\
\hline 6 & Data center - Memory per Machine & $512 \mathrm{~GB}$ & $2 \mathrm{~GB}$ \\
\hline 7 & Data center - Storage per machine & $1 \mathrm{~TB}$ & 100GB \\
\hline 8 & Data center - Available Bandwidth & $10000 \mathrm{MB}$ & $10 \mathrm{MB}$ \\
\hline 9 & Data center - Number of Machines & 240 & 20 \\
\hline 10 & Data center - Number of Processor per Machine & 4 & 4 \\
\hline 11 & Data center - Processor Speed & 10000MIPS & 10000MIPS \\
\hline 12 & Data center - VM policy & Time Shared & Time Shared \\
\hline 13 & User grouping factor & 1000 & 1000 \\
\hline 14 & Request grouping factor & 100 & 100 \\
\hline 15 & No of instructions per request & 250 & 250 \\
\hline 16 & Number of User base & 5 & 6 \\
\hline 17 & Number of data centers & 5 & 3 \\
\hline
\end{tabular}




\begin{tabular}{llcc}
\hline S/N & Metrics & Proposed G-Cloud & Wickremasinghe et al [10] \\
\hline 18 & Established number of virtual machines & 50 & 50 \\
19 & Service Broker & Peak load sharing & Peak load sharing \\
20 & VM load balancer & Throttled & Queuing \\
21 & Established response time / number of data & $56.19 / 5$ data centers & $125.07 / 3$ data centers \\
& centers & CloudAnalyst & CloudAnalyst \\
22 & Cloud simulator used & Implemented with live & Not implemented with live \\
23 & Implementation & course concept & course concept \\
\hline
\end{tabular}

The differences in model metric used in designed GCloud and the research work by [9] were also compared and listed in Table 7 for better understanding on why the designed cloud has a higher performance than that of [9].

Since the amount arrived at for deployment of 5 data centers might be much for the government to start with, it is advised that one data center with 240 servers, 50VM and Throttled Load Balancer with a cost implication of N738, 865, 185.6565 according to Table 3 and energy implication of $368.25 \mathrm{kw} / \mathrm{hr}$ as shown in Table 4 be deployed for a start.

According to Commissioner for Information, Ondo State, the amount spent on letting cloud services from third party is worth about1 billion naira monthly. The old system whose speed is $400 \mathrm{kbps}$ at times experiences network failure which makes the service not to be $100 \%$ available (Direc PC and others).The proposed G-cloud guarantees ease of use and availability of services with $10 \mathrm{Gbps}$, job opportunities, etc.

\section{CONCLUSION AND FUTURE WORKS}

This study has shown the design of a Government Cloud Network for a Developing Economy case study Ondo State that is highly available, fast and provides IaaS and SaaS to different governmental sectors and citizens of the State. Some bench mark were used to design the G-cloud and this G-cloud will be used as back-up for storage purposes, deployment of application, collaborative work, social media and email purposes.

The restriction in access is resolved by proposed Government Cloud that gives access to all citizens, students, State workers and agencies by providing infrastructure as a service and software as a service to government sectors like health, education, finance, agriculture etc.

This research work is recommended for Ondo State Government to adopt; as solution to limited cloud access, limited computing resources, unreliable network and cost of maintaining IT infrastructures; are all encompassed in it and which will enhance their services to citizen and Nigeria at large.

\section{ACKNOWLEDGEMENT}

The authors appreciate God Almighty for the grace given unto them to write this paper to the glory of God. All comments and valuable suggestions of the Reviewer and Chief-Editors are also highly appreciated.

\section{REFERENCES}

[1] Bernd, Z., Klaus, S., Arne, T., and Peter, R., "Cloud Computing in E-Government across Europe: A Comparison, in Technology-Enabled Innovation for Democracy, Government and Governance Lecture Notes in Computer Science," Technology-Enabled Innovation for Democracy, Government and Governance, vol. 8061 of the series Lecture Notes in Comuter Science, pp. 181-195, 2014.

[2] Dahunsi, F. M. and Owoseni, T. M., "Cloud Computing in Nigeria: The Cloud Ecosystem Perspective," Nigerian Journal of Technology, vol. 34, no. 1, pp. 209-216, January 2015.

[3] Dahunsi, F. M., "Cloud Computing For Optimal ICT in Nigeria," pp. 67-72, November 2013, In Conference Proceeding: IEEE International Conference on Emerging and Sustainable Technologies for Power and ICT in a Developing Society.

[4] Layne, K. and Lee, J., Developing Fully Functional eGovernment: A Four Stage Model, Government Information Quarterly, vol. 18, p. 122, 2001.

[5] Mvelase, P., Dlamini, Z., Dlodlo, N. and Sithole, H., "A Business Model for a South African Government Public Cloud Platform," IST-Africa 2014 Conference Proceedings Pauls Cunningham (Eds), IIMC International Information Management Corporation, pp. 1-10, 2014.

[6] Sotomayor, B., Montero, R., Llorente, I. and Foster, I., "Capacity Leasing in Cloud using OpenNebula Engine," http://www.cca08.org/papers/Paper20Sotomayor.pdf (accessed on 20 January 2015)

Vol. 35, No. 3, July 2016 
[7] Kliazovich, D., Pascal, B., and Samee, U.K., "Green Cloud: A Packet Level Simulator of Energy Aware Cloud Computing Data Centers," Public Sector Lead Microsoft Croatia Journal, vol. 10, no. 5, pp. 5-21.

[8] Rodrigo, N. C., Rajiv, R., Anton, B., Cesar, A. F., and Rajkumar, B., "CloudSim: A Toolkit for Modeling and Simulation of Cloud Computing Environments and Evaluation of Resource Provisioning Algorithms," August 2010, Software-Practice and Experience.

[9] Wickremasinghe, B., Virogho, D., and Joane, F., "CloudAnalyst: A CloudSim-based Visual Modeller for Analysing Cloud," Journal of IEEE Computer Society, vol. 16, no. 10, pp. 1-12, 2010.

[10] Wickremasinghe, B., "CloudAnalyst: A CloudSimbased Tool for Modelling and Analysis of Large Scale Cloud Computing Environments," 2009, Available at:http://www.google.com.ng/?gfe $\mathrm{rd}=\mathrm{cr}$ \&ei=ZFDnVLDND8vH8geq1IC4Dg\&gws $\mathrm{rd}=\mathrm{ss} 1 \# \mathrm{q}=$ C1 oudAnalyst: $+\mathrm{A}+$ CloudSimbased + Vis ual+Modeller+for+Analysing+Cloud+Computing +Environments+and+Applications [Accessed 10 September 2014].

[11] Talavera, C. and Santisteban, J., "Design of Network Infrastructure of a Cloud Data Center for Use in Health Sector", 7th Latin American Workshop on Communications, pp 1-6, 2015

[12] Boyce, J. S., "Considering the Design of Cloud Computing Structures on Computer Systems: New Designs in Global Economic Development" Recent Advances in Electrical and Computer Engineering, pp 1-5, 2015.
[13] Theresa, 0. 0. and Alowolodu, O., "Educational Pursuit and Income as Correlates of Family Size in Ondo State, Nigeria," Journal of Social Science, Vol. 23, no 2 pp. 123-127, July 2010.

[14] Polezhaev, P. N., Shukham, A. E., and Ushakov, U. A., "Mathematical Model of Cloud Computing Data Center Based on OpenFlow," Journal of Mathematics of Cloud Computing, vol. 16, no. 9, pp. 1-5, 2010.

[15] Tanenbaum, A. S. and Wetherall, D. J., Computer Networks, Fifth Edition. 2011

[16] Srivatsan, J., "Comparison and Evaluation of OpenSource Cloud Management Software," Royal Institute of Technology, Albacete. vol. 12, no. 20, pp. 20-30, 2012,

[17] Stretch, H., "Symmetric Encryption, Asymmetric Encryption, and Hashing," 2010, Available at webpage: http://www.packetlife.net[Accessed 15 October 2014].

[18] Brown, K., "DELL m905 Poweredge 4-Socket Blade Server, Sierra Microproduct," 2009, available at: http://www.sierramicroproducts.com/dell-m905poweredge-4-socket-blade-server.html [Accessed 21 October 2014].

[19] James, K., "Fibre Channel Switches," 2011, Available at: http://www.cdw.com/shop/product/CiscoMDS-9700-48-port-16-Gbps-Fibre-ChannelSwitching-Module-switch-48/3039811.aspx [Accessed 18 August 2014]. 